\title{
Seasonal Dynamics of Mycorrhizal Colonization in the Rhizosphere of Some Dominant Halophytes
}

\author{
A. FÜZY, T. TÓTH and B. BIRÓ \\ Research Institute for Soil Science and Agricultural Chemistry (RISSAC) of the \\ Hungarian Academy of Sciences, Budapest
}

\section{Introduction}

Attention has already been called to the importance of mycorrhizal symbiosis in plant health and fitness in the literature (BIRÓ et al., 2000, 2005b; CANTRELL \& LiNDERMAN, 2001; HiRREL \& GERDEMANN, 1980). The symbiosis, however, is a sensitive and dynamic connection between the fungi and the host plants. Other microbiological counterpartners therefore can reflect the soil-environmental conditions and its functioning, especially in the case of environments under stress (BIRÓ, 2001; KÁTAI, 1994). During the vegetation period interactions have site-specific spatial and temporal patterns due to the dynamic plasticity of the mycorrhizal symbiosis. Several authors described the annual variability of the symbiotic structures on the same host plants, grown in the same environments (MILLER, 1999; CARVALHO et al., 2001).

The rate of fungal intensity and function can be greatly influenced by biotic and abiotic environmental factors and versatile environmental conditions (BIRÓ et al., 2005a,b). The importance of climatic zonality, thus the value of macro- and microclimatic conditions in the vegetation and in the symbiotic relationship was also reported (ALLEN et al., 1998; BRAUNBERGER et al., 1997; SZILI-KOVÁCS et al., 2000). The geographical site of a certain species can determine the seasonal variability of the soil- and rhizobiological status even on the same soil types (BIRÓ, 2001; VAN DUIN et al., 1990; BIRó et al., 2002).

Mycorrhizal fungi are obligate endosymbionts of about $80 \%$ of the higher plants. The ratio of arbuscular mycorrhizal (AM) colonization is greatly affected by the host plants and their physiological status, providing a dynamic fluctuation during the vegetation periods (BIRÓ et al., 2005a). Relatively few studies have been carried out, however in this respect on the Hungarian steppe (HILDEBRANDT et al., 2001; LANDWEHR et al,. 2002).

The present work's aim was the regular monitoring of mycorrhizal colonization on the most dominant halophytes to understand the: 1 . mechanism of seasonal or annual variability; 2 . the interrelations with the main soil characteristics and water

Correspondence to: BORBALA BIRÓ, Research Institute for Soil Science and Agricultural Chemistry of the Hungarian Academy of Sciences, H-1022 Budapest, Herman Ottó út 15. Hungary.E-mail: biró@rissac.hu 
fluctuations; 3. the role of zonality in the species-specific characteristics between the macro- and the microsymbionts; and 4 . the site-climatic differences at two selected saline sites in Hungary.

\section{Materials and Methods}

\section{Site description and sampling procedures}

Soil and root samples were collected from the rhizosphere of the most typical halophytes, such as the Plantago maritima, Aster tripolium, Artemisia santonicum, Puccinellia limosa, Festuca pseudovina and Lepidium crassifolium, grown on the

Table 1

Soil characteristics of the selected sampling sites (Hungary, 2001)

\begin{tabular}{|c|c|c|}
\hline Measured parameters & Apajpuszta (Site A) & Zabszék (Site Z) \\
\hline Coordinates & $47^{\circ} 5,2^{\prime} \mathrm{N} ; 1^{\circ} 5,8^{\prime} \mathrm{E}$ & $46^{\circ} 50,6^{\prime} \mathrm{N} ; 19^{\circ} 10,6^{\prime} \mathrm{E}$ \\
\hline Main features & $\begin{array}{l}\text { grassland, occasionally } \\
\text { pastured }\end{array}$ & $\begin{array}{l}\text { meadow, influenced by the water } \\
\text { fluctuation of lake Zabszék }\end{array}$ \\
\hline Soil type & solonetz & solonchak \\
\hline Specific salts & $\mathrm{Na}_{2} \mathrm{CO}_{3}-\mathrm{Na}_{2} \mathrm{SO}_{4}$ & $\mathrm{Na}_{2} \mathrm{CO}_{3}$ \\
\hline $\mathrm{pH}$ & $8.51-9.64$ & $9.01-9.72$ \\
\hline $\begin{array}{r}\text { EC of } 1: 2.5 \text { soil:water } \\
\text { suspension }\left(\mathrm{dS} \cdot \mathrm{m}^{-1}\right)\end{array}$ & $0.38-0.82$ & $0.70-1.17$ \\
\hline $\mathrm{OM}(\%)$ & $0.86-1.78$ & $0.71-1.14$ \\
\hline Clay content (\%) & $9-26$ & 8-18 \\
\hline
\end{tabular}

Table 2

Meteorological data of the Kiskunság region during the two sampling periods

\begin{tabular}{|l|c|c||c|c|}
\hline \multirow{2}{*}{ Months } & \multicolumn{2}{|c||}{2001} & \multicolumn{2}{c|}{2002} \\
\cline { 2 - 5 } & $\begin{array}{c}\text { Precipitation } \\
(\mathrm{mm})\end{array}$ & $\begin{array}{c}\text { Temperature } \\
\left({ }^{\circ} \mathrm{C}\right)\end{array}$ & $\begin{array}{c}\text { Precipitation } \\
(\mathrm{mm})\end{array}$ & $\begin{array}{c}\text { Temperature } \\
\left({ }^{\circ} \mathrm{C}\right)\end{array}$ \\
\hline January & $69(-)^{*}$ & $1.1(-)^{*}$ & $11(17)^{*}$ & $1.8(3.4)^{*}$ \\
February & $2(-)^{*}$ & $3.1(-)^{*}$ & $17(13)^{*}$ & $5.7(5.6)^{*}$ \\
March & $64(43)^{*}$ & $8.7(5.8)^{*}$ & $22(6)^{*}$ & $7.8(8.0)^{*}$ \\
April & $37(20)^{*}$ & $10.2(9.0)^{*}$ & $36(28)^{*}$ & $11.0(11.4)^{*}$ \\
May & $17(11)^{*}$ & $17.1(15.2)^{*}$ & $41(20)^{*}$ & $19.0(18.3)^{*}$ \\
June & $94(84)^{*}$ & $17.9(17.0)^{*}$ & $57(48)^{*}$ & $21.3(22.2)^{*}$ \\
July & $127(55)^{*}$ & $21.5(21.5)^{*}$ & $34(16)^{*}$ & $23.4(23.4)^{*}$ \\
August & $21(17)^{*}$ & $22.1(22.3)^{*}$ & $75(61)$ & $21.3(20.9)^{*}$ \\
September & $98(85)^{*}$ & $14.8(14.3)^{*}$ & $73(73)^{*}$ & $15.1(13.1)^{*}$ \\
October & $14(1)^{*}$ & $13.9(13.3)^{*}$ & $30(26)^{*}$ & $10.6(10.3)^{*}$ \\
November & $39(41)^{*}$ & $3.0(6.2)^{*}$ & $25(19)^{*}$ & $7.5(6.3)^{*}$ \\
December & $13(15)^{*}$ & $-5.1(0.1)^{*}$ & $45(-)^{*}$ & $-1.7(-)^{*}$ \\
\hline
\end{tabular}

*data of a 20-day period before the root and soil sampling 
saline soils of two characteristic sites (site A: Apajpuszta, site Z: Zabszék) in Hungary. The soil and root samples contained the rhizosphere of at least five plants grown on the same spot (the similar salt concentration was measured by a portable field conductometer).

The most important soil physical and chemical characteristics are given in Table 1. Data on the weather conditions, such as the temperature and the precipitation at the sampling sites for the two vegetation periods are summarized in Table 2.

\section{Soil and root analyses}

Samples of $1 \mathrm{~g}$ fresh lateral roots of the main halophytes were randomly removed, cleansed in tap water and stored in $70 \%$ alcohol before examining the AMF colonization. After storage root samples were cut to approximately $1 \mathrm{~cm}$ segments, boiled in a $15 \% \mathrm{KOH}$ solution for 40 minutes, stained with aniline blue and fixed in 40\% lactic acid, as it was suggested by PHILLIPS and HAYMAN (1970). After these procedures, the colonization characteristics were studied according to the five-class system of TROUVELOT et al. (1986). A 100×, 200× or $400 \times$ magnification was used by an Olympus microscope to assess the accurate AMF structures in the root segments.

The presence and abundance of hyphae, vesicles and arbuscules were determined in 30 root segments for each sample. Frequency and intensity of mycorrhizal colonization (F\%, M\%) and the absolute and relative arbusculum richness (A\%, a\%) were estimated and calculated after the assessments.

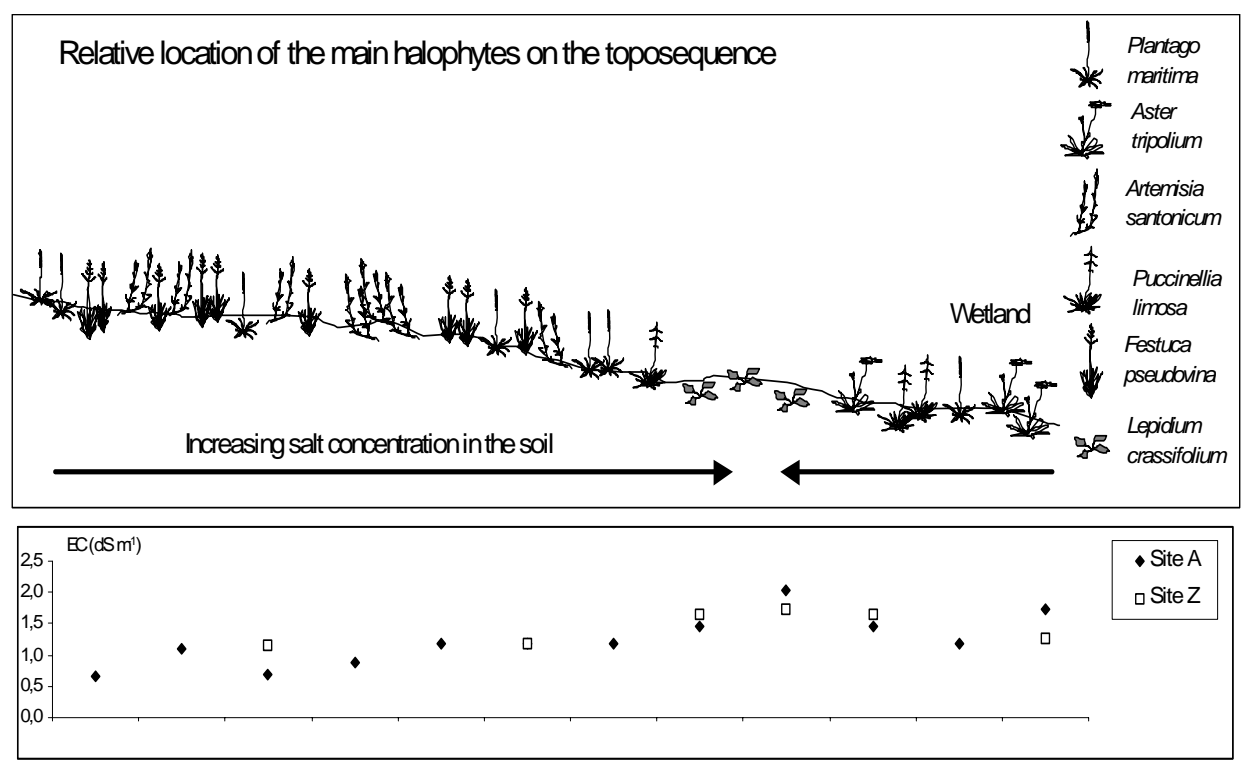

Fig. 1

Relative location of the 6 main halophyte species on the toposequence and the concomittant salt concentration (EC, dS $\cdot \mathrm{m}^{-1}$ ) at the study areas (site A: Apajpuszta and site Z: Zabszék) 
Statistical analyses. - One-way variance analysis was performed to follow the seasonal changes. Results are shown in figures, including the least significant differences $\left(\mathrm{LSD}_{5 \%}\right.$.)

\section{Results and Discussion}

\section{Host specificity in mycorrhizal colonization}

Fig. 1 shows the location of the investigated plant species along the toposequence in Apajpuszta. Plantago maritima is a common plant and can be found at all points of the toposequence, except in the bare spots. Artemisia santonicum and Festuca pseudovina originate from an association of the higher altitudes, while Aster tripolium and Puccinellia limosa are the dominant species in wetland elevation zones (the right side of Fig. 1). In the bare spots the only plant is the Brassicaceae Lepidium crassifolium.

The colonization values of the five investigated plant species are presented in Fig. 2. In the case of higher altitude with less salt in the soil more than half of the root system is colonized (Plantago maritima, Artemisia santonicum and Festuca pseudovina), at lower altitude (5-20 cm lower) with more salt in the soil the colonization rate is lower, but remarkable (Puccinellia limosa), or seasonally can be quite high (Aster tripolium). During summer periods the symbiosis is detectable also on Lepidium crassifolium, which is generally known as a non-mycotrophic halophyte. Species specificity is recognizable in the mycorrhizal functioning of the selected investigated plants, as well. Arbusculum richness was especially high in the case of Plantago maritima, while it was almost zero for Puccinellia limosa. According to these results it can be stated that the colonization ratio of the arbuscular mycorrhizal fungi in the rhizosphere of the most dominant halophytes is greatly determined by a host-specificity, as it was also established by CARVALHO et al. (2001). In addition to these plant physiology driven properties, the physical and chemical characteristics of the saline soils and the weather conditions can dramatically affect the temporal and spatial variability of the host-mycorrhizal symbiosis, as shown in the following.

\section{Site variability of the mycorrhizal colonization}

Two characteristic saline sites were selected for the study. Site A (Apajpuszta) has meadow solonetz soil and is occasionally pastured by sheep. Site Z (Zabszék) has a solonchak soil in the vicinity of the Zabszék lake, and therefore, it has a periodic water flooding situation. The main soil characteristics of the sites are summarized in Table 1.

Fig. 3 shows the arbuscular mycorrhizal colonization parameters of two selected halophytes. Apparently a much higher mycorrhizal colonization (M\%) occurred on both plant species at the Apaj study area. The intensity of mycorrhizal colonization at this site was between $40-100 \%$ and only $20-60 \%$ as an average at the Zabszék site on Aster tripolium. This plant had a higher value of arbusculum richness (A\%) 

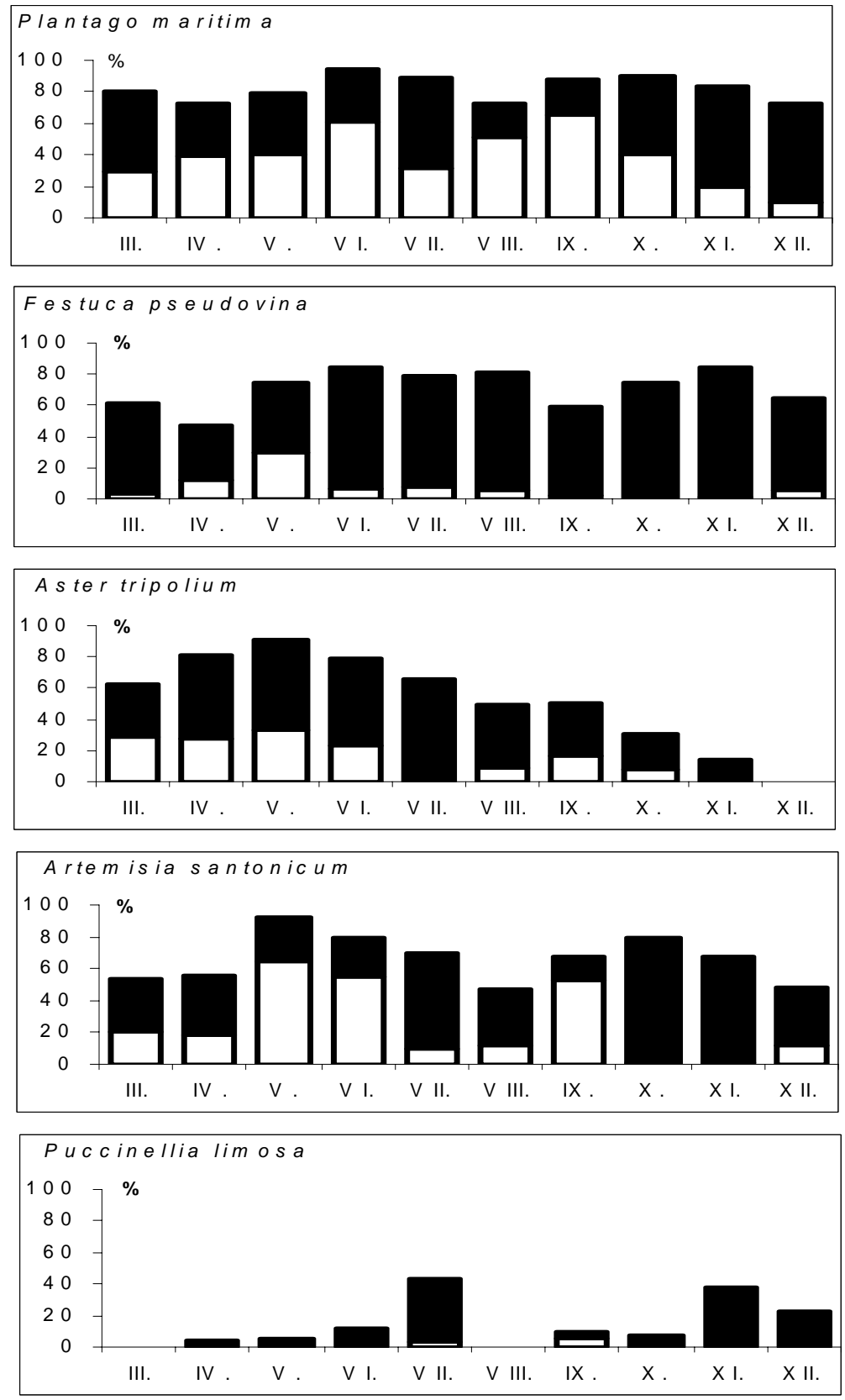

Fig. 2

Mycorrhizal colonization of dominant halophytes at Site A (Apajpuszta) in 2001 from March to December. The whole column represents the colonization intensity (M\%), the white part of the column stands for the arbusculated part of the root system (A\%) 

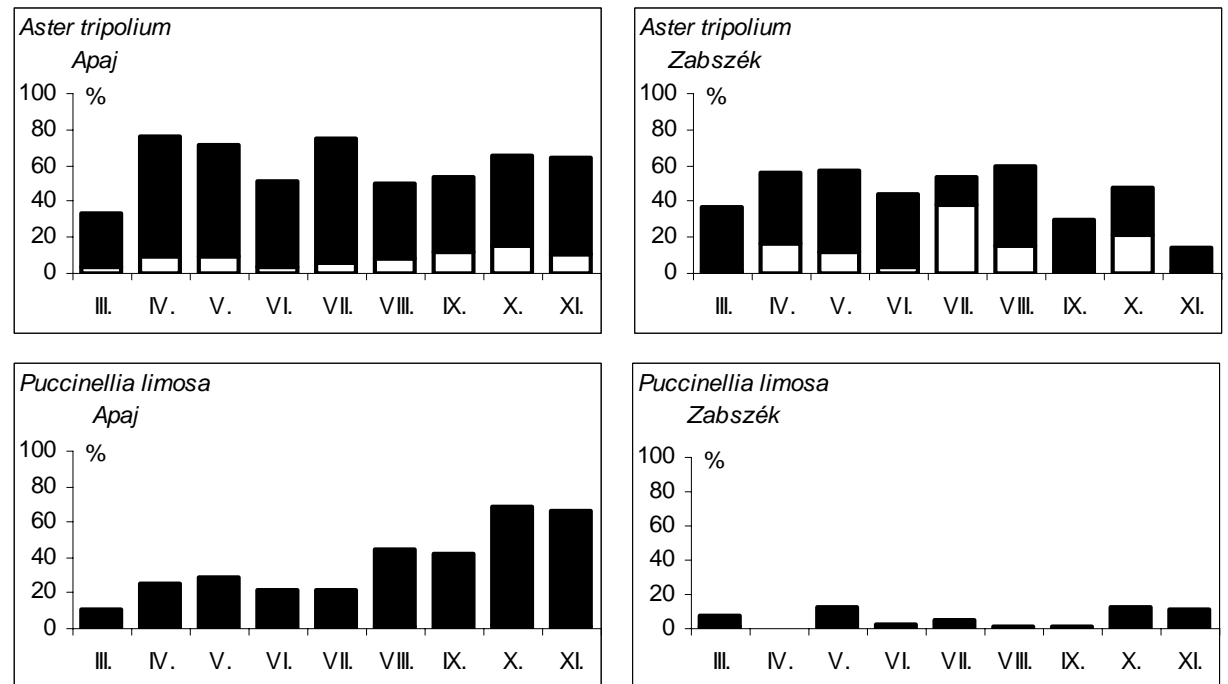

Fig. 3

Mycorrhizal colonization of two selected halophytes at the two salt affected sites in 2002 from March to November. The whole column represents the colonization intensity (M\%), the white part of the column stands for the arbusculated part of the root system (A\%)

in comparison with the Puccinellia limosa, which had almost zero arbuscularity at both sites. A quite high A\% value was recorded only in July on the Aster tripolium grown in the Zabszék area. This intensive colonization reflects an improved functioning of the AM fungi under the highly stressed environmental conditions (i.e. in summer), similarly to earlier findings (FÜZY et al., 2003; BIRÓ et al., 2000). At the Zabszék site the water content of the topsoil was found to be near zero, and the host plant, Aster tripolium has a greater inductive capacity for the symbiosis, to survive the natural stress conditions. In other periods of the year water fluctuation is intensive at this site, therefore the mycorrhizal colonization value rather depends on the soil's water content and the parallel severity of other environmental stresses (like high or low temperatures, salt content etc.) Such importance of the soil water conditions in the environment is already a well-known phenomenon (VARALLYAY, 1999). On the long-term, however, characteristic site-specificity can be recorded on saline soils, which can be reflected on the basis of the plant-microbe interactions, similarly to earlier findings on heavy metals (KÁDÁR et al., 2001).

\section{Temporal changes in mycorrhizal colonization}

Root samples of Plantago maritima were collected at four different points on the Apajpuszta site. It was possible, therefore to compare the colonization variability on the same host plant at a particular site during the vegetation period. Data presented on Fig. 4 show the mycorrhizal values from March 2001 to February 2002 with monthly frequency. An especially characteristic dynamism of the colonization 
pattern was found on the Plantago maritima, known to be a good-mycotroph plant species. Mycorrhizal colonization increased significantly during the spring period up to the early summer (to June). A concomitant decrease was observed, however, from June to July, and an enhanced mycorrhizal intensity (M\%) was recorded be-
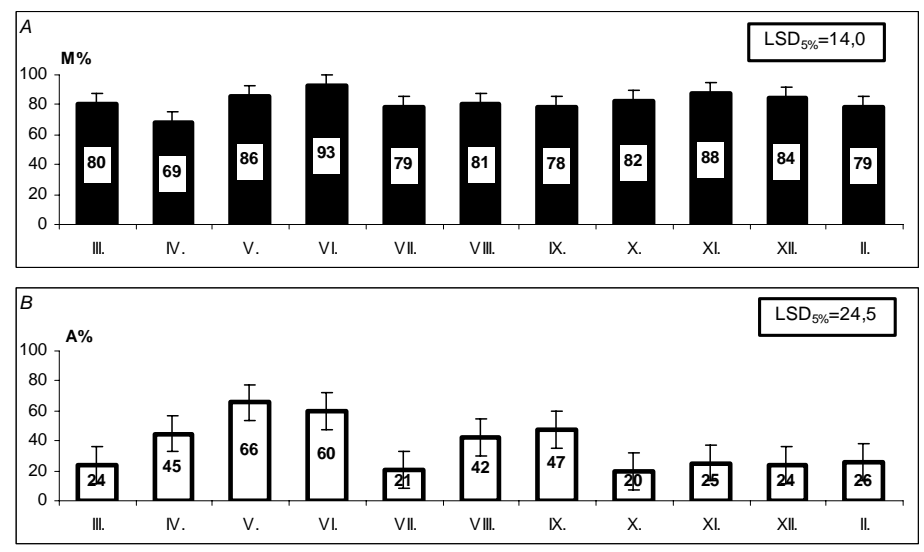

Fig. 4

The mycorrhizal colonization of Plantago maritima at site A (Apajpuszta) in 2001 A. Mycorrhizal intensity (M\%). B. Arbusculum richness (A\%). The figures show the mean data and $\mathrm{LSD}_{5 \%}$ values, as a result of one-way variance analysis

tween July and November. A similar tendency was also observed for the arbusculum richness (A\%) values, with two characteristic maximum levels in May-June and August-September. The importance of the AM fungi in the nutrient supply is more pronounced in these periods, which may intensify the functioning of the microsymbiont partner.

The decrease in mycorrhizal colonization during the summer period is correlatable by the negative effect of high temperature and drought, which are known stressors in environmental studies (HILDEBRANDT et al., 2001; LANDWEHR et al., 2002). In those stressed soils the stress-buffering effect of the arbuscular mycorrhizal fungi can be developed (RUIZ-LOZANO et al., 1996; BIRÓ et al., 2005b). On a long-term level, however, the species diversity and the specific functioning of the fungi may also be reduced (HILDEBRANDT et al., 2001; LANDWEHR et al., 2002). According to this finding, it is assumed that the highly salt-tolerant Glomus geosporum is the main mycorrhiza type in saline soils that can be involved in the stress reduction of the most dominant halophytes, shown in this study. 


\section{Summary}

Dominant halophytes, such as Plantago maritima, Aster tripolium, Artemisia santonicum, Puccinellia limosa, Festuca pseudovina and Lepidium crassifolium were monitored for their colonization by arbuscular mycorrhizal fungi (AMF) for two vegetation periods, sampled by monthly frequency. Two saline sites (A: Apajpuszta and Z: Zabszék) were selected for the survey due to their similar physical and chemical soil characteristics (including the salt level and salt specific anions) and the distinct site use (pasturing or not) or water regime (as drought or temporally flooded at the vicinity of the Zabszék lake).

Colonization of arbuscular mycorrhizal fungi greatly depended on the plant species and their physiological status, such as the mycotroph or non-mycotroph character. In this respect the highest mycorrhizal intensity (M\%) and arbusculum richness (A\%) was found on the Plantago maritima, while Puccinellia limosa was the less dependent species on mycorrhiza fungi.

A characteristic seasonal dynamism was found at both saline sites, for all sampled halophytes. A maximum mycorrhizal colonization was recorded in late spring and early summer, when there was an increased plant-physiological initiative for the helpful symbiosis (i.e. intensive vegetative and/or generative phases of the hosts).

The rate of fungal intensity in the root system (M\%), and especially the arbusculum richness $(\mathrm{A} \%)$ on the other hand was found to be dependent on the site use and the water fluctuation in the soils. A more versatile dynamism of the mycorrhizal colonization was found therefore at the vicinity of the Zabszek lake with the permanent water fluctuations. Under more drought stressed conditions an increased mycorrhizal colonization and functioning (arbusculum richness) was found, generally preceeding the high environmental stress, which was deleterious for both symbiont partners. Such mycorrhizal dynamism in the rhizosphere, however, seems to be a common strategy between the hosts and the microsymbionts in the "struggle for life” process in the Hungarian steppe.

The present work was supported by the Hungarian National Scientific Research Fund (OTKA) (Grants T0 46610 and $\mathrm{T}$ 37731) and the EU Framework-5 MYCOREM project.

Key words: arbuscular mycorrhiza, halophytes, seasonal dynamism, drought stress, salt stress

\section{References}

ALLEN, E. B. et al., 1998. Disturbance and seasonal dynamics of mycorrhizae in a tropical deciduous forest in Mexico. Biotropica. 30. 261-274.

BIRÓ, B., 2001. Plants with symbiont strategies and their role in drought-tolerance along two climate-gradients in Hungary. In: Oecology in the $21^{\text {st }}$ Century. I. Case studies 
(Eds: BoRHIDI, A. \& BotTA-DuKÁT, Z.). (In Hungarian) 173-175. Hungarian Academy of Sciences. Budapest.

BIRÓ, B., VILLÁNYI, I. \& KÖVES-PÉCHY, K., 2002. Abundance and adaptation levels of some soil microbes in salt-affected soils. Agrokémia és Talajtan. 50. 99-106.

BIRÓ, B. et al., 2000. Interrelations between Azospirillum and Rhizobium nitrogen-fixers and arbuscular mycorrhizal fungi in the rhizosphere of alfalfa at sterile, AMF-free or normal soil conditions. Appl. Soil Ecol. 461. 1-10.

BIRÓ, B. et al., 2005a. Mycorrhizal functioning as part of the survival mechanisms of barley (Hordeum vulgare L.) at long-term heavy metal stress. Acta Biol. Szegediensis. 49. 65-68.

BIRÓ, B. et al., 2005b. Role of the beneficial microsymbionts on the plant fitness. In: Soil Biology. Vol. 7. Microbial Activity in the Rhizosphere. (Eds.: MuKERJI, K. G. et al.) 265-296. Springer Verlag. Berlin.

Braunberger, P. G., ABbotT, L. K. \& Robson, A. D., 1997. Early vesiculararbuscular mycorrhizal colonisation in soil collected from an annual clover-based pasture in a Mediterranean environment: Soil temperature and the timing of autumn rains. Australian J. Agricult. Research. 48. (1) 103-110.

Cantrell, I. C. \& Linderman, R. G., 2001. Preinoculation of lettuce and onion with VA mycorrhizal fungi reduces deleterious effects of soil salinity. Plant and Soil. 233. (2) 269-281.

Carvalho, L. M., Cacador, I. \& Martins-LucaO, M. A., 2001. Temporal and spatial variation of AM fungi in salt marsh plants of the Tagus estuary (Portugal). Mycorrhiza. 11. 303-309.

FÜZY, A., BIRó, B. \& TóTH, T., 2003. Plant-soil interactions and soil properties on some Hungarian saline soils. (In Hungarian) Természetvéd. Közl. 10. 64-69.

HILDEBRANDT, U. et al., 2001. Arbuscular mycorrhizal colonisation of halophytes in Central European salt marshes. Mycorrhiza. 10. 175-183.

HiRREL, M. C. \& GeRDEMANN, J. W., 1980. Improved growth of onion and bell pepper in saline soils by two vesicular-arbuscular mycorrhizal fungi. Soil Sci. Soc. Am. J. 44. 654-656.

KÁDÁR, I. et al., 2001. Effect of microelement loads on peas grown on calcareous chernozem soil. II. Element uptake, quality and root symbiosis. (In Hungarian) Agrokémia és Talajtan. 50. 83-101.

KÁTAI, J., 1994. The effect of different ways of nutrient supply on the soil microflora and activity. In: Soil, Plant and Environment Relationships. (Ed.: NAGY, J.) 210219. University Press. Debrecen.

LANDWEHR, M. et al., 2002. The arbuscular mycorrhizal fungus Glomus geosporum in European saline, sodic and gypsum soils. Mycorrhiza. 12. 199-211.

Miller, S. P., 1999. AM colonisation of semi-aquatic grasses along a wide hydrogeologic gradient. New Phytol. 145. 145-155.

PHILliPS, J. M. \& HAYMAN, D. S., 1970. Improved procedures for clearing roots and staining parasitic and VAM fungi for rapid assessment of infection. Trans. Br. Mycol. Soc. 55. 158-161.

Ruiz-LozAno, J. M., Azcón, R. \& Gómez, M., 1996. Alleviation of salt-stress by AM Glomus species in Lactuca sativa. Physiol. Plantarum. 98. 767-772. 
SzILI-KovÁCS, T. et al., 2000. Restoration of sandy grasslands through the immobilization of soil nitrogen. 1. Laboratory incubation experiments. Agrokémia és Talajtan. 49. 491-504.

Trouvelot, A., Kought, J. L. \& Gianinazzi-Pearson, V., 1986. Mesure du taux de mycorhization VA d'un systéme radiculaire. Recherche de méthodes d'estimation ayant une signification fonctionnelle. In: Ler Symposium Europeen sur les Mycorrhizes. 217-221. INRA. Paris.

VAN DUIN W. E., RozemA, J. \& ERNST, W. H. O., 1990. Seasonal and spatial variation in the occurrence of vesicular-arbuscular (VA) mycorrhiza in salt marsh plants. Agricult. Ecosyst. Environ. 29. 107-110.

VÁrAllyay, GY., 1999. Water, Soil and Environment. In: Soil, Plant and Environment Interactions. (Eds: NAGY, J. \& NÉMETH, T.) 95-119. (In Hungarian) Debrecen Agric. Univ. and RISSAC. Debrecen. 